\title{
EL PROPÓSITO DE INCORPORACIÓN OBLIGATORIA DEL TRABAJADOR INDEPENDIENTE O AUTÓNOMO AL SISTEMA DE SEGURIDAD SOCIAL CHILENO. UNA TAREA EN DESARROLLO
}

\author{
Jorge Drago Morales* \\ Universidad de Chile
}

\section{GENERALIDADES}

Se ha dicho que la incorporación obligada de todo trabajador independiente a un sistema de seguridad social contributivo si bien es deseable y conveniente, no siempre es factible. En efecto, obstan a tan loable intención razones tales como la dificultad de fiscalizar el cumplimiento de la cotización, a diferencia del trabajador subordinado o dependiente, que tiene un empleador a quien se hace responsable del pago, al cual se le puede exigir y ejecutar, e incluso hay terceros responsables solidaria y subsidiariamente. También los trabajadores independientes o por cuenta propia, especialmente no calificados, tienen ingresos bajos, y la cotización disminuiría en forma importante su saldo líquido. Por último, el sector de los trabajadores independientes es muy heterogéneo, y así se puede distinguir al menos los siguientes segmentos: empresarios o empleadores con trabajadores bajo su dependencia y profesionales liberales y técnicos, todos los cuales tienen rentas normalmente mayores; empresarios o trabajadores por cuenta propia sin dependientes o subordinados, como los micro empresarios, dueños de empresas unipersonales, comerciantes ambulantes, trabajadores de la construcción, de la agricultura, campesinos y parceleros, de oficios al público como jardineros, plomeros, suplementeros, artesanos, trabajadores eventuales, esporádicos, etc., todos de ingresos notoriamente menores o bajos.

De esta forma, resulta compleja una afiliación y contribución obligada amplia, que incluya a la gran mayoría de los trabajadores independientes o por cuenta propia, lo que lleva a que el legislador deba ejercer opciones al respecto, como ha ocurrido en Chile.

Es así como el menú de opciones ha estado restringido a un sector del segmento de los trabajadores independientes con mayor capacidad contributiva, toda vez que no parece prudente obligar a cotizar a los de ingresos más bajos, lo que podría inducirlos a apartarse de la legalidad y de la formalidad de sus oficios. A estos más bien se les puede acoger a programas de seguridad social no contributiva, o contributiva pero con importante financiamiento fiscal subsidiario, o con el complemento de recursos de fondos solidarios aportados por los trabajadores de mayor capacidad contributiva.

* Abogado. Profesor de Derecho del Trabajo y de la Seguridad Social, Facultad de la Derecho, Universidad de Chile. 
En Chile se ha optado, como se verá, por los trabajadores que obtienen básicamente rentas a través de honorarios y los que emiten boletas de servicios, los que por esta razón son también más fácilmente fiscalizables, sin perjuicio que constituyen un sector de mayores ingresos.

Cabe agregar, que en el país, los trabajadores independientes y por cuenta propia alcanzan a un porcentaje aproximado superior al $22 \%$ de la fuerza ocupada laboral, y se distribuyen en un $4,1 \%$ de empleadores o empresarios, y en un $18,55 \%$ de trabajadores profesionales y por cuenta propia, sin considerar a los trabajadores familiares no remunerados, que alcanzan a un $1,3 \%{ }^{1}$. Sus ingresos, en el caso de los primeros, son muy superiores al promedio de los trabajadores dependientes, en proporción de 6 a 1, aproximadamente, y levemente por sobre el mismo, en los segundos, siempre que no se trate de profesionales o técnicos, que corresponden a un $2 \%$, y que tienen ingresos por sobre el promedio de los dependientes en proporción de 4 a 1, y de 3 a 1 respectivamente.

Corresponde considerar que los trabajadores independientes de mayores ingresos, como empresarios con trabajadores dependientes, profesionales universitarios como médicos, abogados o ingenieros, entre otros, y socios o directores de sociedades, todos los cuales pueden tener mayor capacidad de ahorro, prefieren en la práctica recurrir a sistemas de auto seguro, para cubrir eventuales necesidades futuras, como realizar inversiones financieras, depósitos de ahorro, adquirir bienes raíces que les proporcionen alguna renta, reinvertir en sus propias empresas, tomar seguros de vida, de salud, etc. Todo lo cual les aleja del interés por afiliarse y cotizar obligadamente a un organismo previsional, si los ahorros a través de las cotizaciones y aportes que deban efectuar escapan a su manejo en el corto o mediano plazo, y sólo podrán serles de utilidad después de 30, 40 o más años de espera, cuando se traduzcan en pensiones, salvo podría ser el caso de la invalidez o muerte prematura, en que la pensión se devenga ocurrido el siniestro, previo un reducido período de cotización, por regla general.

Sin duda que la incorporación de estos trabajadores es un desafío de importancia a los propósitos del legislador de incorporarlos en forma obligatoria a un régimen previsional. Se debe remar contra una cultura muy arraigada y difundida en este sector de trabajadores.

\section{DEFINICIONES}

Como una manera de aproximarnos al tema parece conveniente dilucidar el concepto de trabajador independiente, que no siempre es preciso. La OIT ha señalado que empleos independientes son aquellos en los que la remuneración (o renta) depende directamente de los beneficios derivados de los bienes o servicios producidos, contraponiéndolo al empleo asalariado, en el cual los titulares reciben una remuneración que no depende directamente de los ingresos de la unidad productiva para la cual trabajan, y cuentan con contratos de trabajo implícitos o explícitos.

La misma OIT distingue al interior del empleo independiente, en primer lugar a los empleadores, que son aquellos trabajadores que por su cuenta y riesgo, o con uno o más socios, han contratado a una o más personas para que trabajen para ellos en un período continuo. Luego, están los trabajadores por cuenta propia, que son aquellos que trabajando igualmente por su cuenta y riesgo, o con uno o más socios, no han contratado a ningún asalariado de manera continua que trabaje para ellos. En tercer lugar se encontrarían los independientes familiares auxiliares, que

El total nacional de trabajadores ocupados sería de 7.734.480; los empleadores 318.540, y los por cuenta propia 1.435.490. Los familiares sin remuneración 101.220. Los dependientes o asalariados 5.540.800. Fuente: Nueva Encuesta Nacional de Empleo. INE. Marzo de 2013. 
serían los que laboran en un establecimiento dirigido por algún familiar y que generalmente viven en su mismo hogar, y no perciben formalmente remuneración. ${ }^{2}$

Esta clasificación general de la OIT es bastante ilustrativa y amplia, utilizando como elemento diferenciador entre los trabajadores independientes la utilización de trabajadores bajo su dependencia, que serían los independientes empleadores, de los que no los tienen, que serían los independientes por cuenta propia, y agrega un sector especial, el de los familiares auxiliares o colaboradores, que si bien no son de gran ocurrencia, existen realmente, en especial en economías más atrasadas, o de base campesina, y respecto de ellos no es fácil la configuración de un vínculo de subordinación o dependencia laboral, por lo que no quedaría otra salida que considerarlos trabajadores independientes.

Pareciera que el segmento de mayor interés para la seguridad social debiera ser el que corresponde al concepto de trabajador independiente por cuenta propia, entre los cuales es posible considerar, generalmente, al micro empresario, o dueño de una actividad u oficio o empresa unipersonal, no obstante que por sus bajos ingresos significan una limitante para su incorporación obligatoria a un sistema contributivo.

Pues bien, el artículo $3^{\circ}$ letra c) del Código del Trabajo, ${ }^{3}$ define al trabajador independiente, en los siguientes términos:

"Para todos los efectos legales se entiende por :

c) trabajador independiente: aquel que en el ejercicio de la actividad de que se trata no depende de empleador alguno ni tiene trabajadores bajo su dependencia.

El empleador se considerará trabajador independiente para los efectos previsionales".

De esta definición del Código del Trabajo, que para efectos de la aplicación de este cuerpo legal solo tiene incidencia en materia sindical, al incluir en una clasificación de estas organizaciones a los sindicatos de trabajadores independientes, podríamos concluir que se está comprendiendo en ella lo que en doctrina es el trabajador por cuenta propia, sin trabajadores bajo su dependencia, y el empleador, que dispone de tales trabajadores, sería considerado igualmente independiente, es decir, como por cuenta propia, pero para los efectos previsionales, con lo cual quedaría en situación de poder ser sujeto de un sistema de seguridad social para trabajadores independientes en general. De esta manera, la definición dada por nuestro Código del Trabajo sería concordante con la de la OIT antes señalada.

En el país, la iniciativa de incorporar a los trabajadores independientes en términos amplios a la seguridad social, tiene su base constitucional. El artículo 19, de la Constitución Política de la República de Chile de $1980,{ }^{4}$ que consagra la gama de derechos fundamentales, establece:

"La Constitución asegura a todas las personas:

$\mathrm{N}^{\circ} 18$ El derecho a la seguridad social.

2 Taxonomía basada en Clasificación Internacional de Categorías de la Ocupación. CISE-93.

3 El Código del Trabajo ha sido fijado en su texto refundido, coordinado y sistematizado por el DFL No 1, de 2002, del Ministerio del Trabajo y Previsión Social, publicado en el Diario Oficial de 16.01.2003.

4 El decreto supremo No 100, de 2005, del Ministerio Secretaría General de Gobierno, publicado en el Diario Oficial de 22.09.2005, aprueba el texto refundido y coordinado de la Constitución Política de la República de Chile, de 1980. 
La acción del Estado estará dirigida a garantizar el acceso de todos los habitantes al goce de prestaciones básicas uniformes, sea que se otorguen a través de instituciones públicas o privadas...".

De esta forma, el derecho a la seguridad social se incorpora de manera explícita como un derecho fundamental en favor de toda persona, en términos amplios y universales a todos los habitantes, comprendiendo sin duda a los trabajadores independientes en general.

\section{REGULACIÓN LEGAL PREVISIONAL DEL TRABAJADOR INDEPENDIENTE BREVE TRAYECTORIA HISTÓRICA:}

Con anterioridad al Decreto Ley $\mathrm{N}^{\circ} 3.500,{ }^{5}$ que entró en vigencia el $1^{\circ}$ de mayo de $1981, \mathrm{y}$ que estableció en el país el denominado Nuevo Sistema de Pensiones, basado en la capitalización individual y en una administración privada de los Fondos a través de las Administradoras de Fondos de Pensiones -AFP-, en Chile existía solo un régimen legal que se preocupaba de la protección previsional del trabajador independiente, en términos más o menos limitados por la actividad genérica desarrollada, asimilándolo a la situación del obrero, como trabajador de menores ingresos, como lo fue el inciso $3^{\circ}$ del artículo $2^{\circ}$ de la ley $N^{\circ} 10.383$, del año 1952 , norma legal que estableció el seguro social obligatorio para los obreros, al señalar:

"Quedan, igualmente, sometidos a esta obligación, ( de afiliación a este régimen previsional) los trabajadores independientes, como artesanos, artistas, pequeños industriales, pequeños comerciantes fijos o ambulantes o personas que realizan oficios o prestan servicios directamente al público, en calles, plazas, portales o almacenes, siempre que su renta anual total no exceda de tres ingresos mínimos anuales".

De esta suerte, era obligatoria la afiliación al ex Servicio de Seguro Social, que administraba la ley $\mathrm{N}^{\circ} 10.383$, de los trabajadores que desempeñaban únicamente ciertos oficios como los antes indicados, y siempre que no obtuvieren una renta anual superior equivalente actualmente a $\$ 6.948 .000$, es decir, a \$579.000 mensuales, que expresados en dólares para una mejor comprensión, significan US\$14.475 y US\$1.200, respectivamente ${ }^{6}$.

De esta forma, si bien existía una afiliación obligatoria para los trabajadores independientes lo era a la vez restringida, tanto por la actividad desempeñada que debía corresponder a las indicadas en la ley, como por ingreso o renta. En otros términos, si los trabajadores por cuenta propia cumplían otras labores o sus rentas eran superiores a las señaladas, no tenían la posibilidad de acceder a un régimen previsional del Antiguo Sistema de Pensiones por esta vía.

Cabe consignar, que si bien la ley $\mathrm{N}^{\circ} 10.383$ se encuentra vigente, y es administrada por el Instituto de Previsión Social, IPS, no es posible actualmente la afiliación de los trabajadores independientes a su normativa, sino que al Nuevo Sistema de Pensiones, del D.L. N 3.500, de 1980.

Lo expuesto es sin perjuicio de una variada legislación que se aprobó para ciertas actividades específicas de trabajadores independientes o por cuenta propia, como sucedió, entre numerosas otras, con actores de teatro, cine, radio, televisión, circenses, ballet, cantantes y coristas,

\footnotetext{
El decreto ley No 3.500, de 1980, fue publicado en el Diario Oficial de 13.11.1980.

Se ha utilizado un valor promedio de \$480, por 1US\$, a abril de 2013.
} 
coreógrafos, folkloristas, autores teatrales, libretistas y compositores, etc., a todos los cuales la ley $\mathrm{N}^{\circ}$ 15.478, de 1964, incorporó al régimen de previsión de la ex Caja de Empleados Particulares. Asimismo, ocurrió con otro gremio como los conductores de automóviles de alquiler al servicio del público, o taxistas, incorporados igualmente a este régimen, por la ley $\mathrm{N}^{\circ} 15.722$, de 1964 ; y entre los profesionales, a los abogados de ejercicio libre de la profesión, que la ley $\mathrm{N}^{\circ} 10.627$, de 1952, incorporó a la ex Caja Nacional de Empleados Públicos y Periodistas.

Cabe agregar, que todos los regímenes previsionales administrados por las instituciones o ex Cajas antes nombradas de carácter fiscal o semifiscal, se encuentran actualmente vigentes, aún cuando fusionados desde el punto de vista administrativo en un servicio público denominado Instituto de Previsión Social, IPS, continuador del ex Instituto de Normalización Previsional o INP, y forman parte de lo que se llama el Antiguo Sistema de Pensiones. No obstante, rigen para todos los trabajadores que se hubieren afiliado a tales regímenes de las ex Cajas con anterioridad al $1^{\circ}$ de mayo de 1981, dado que a partir de esta fecha sólo han podido hacerlo al Nuevo Sistema de Pensiones, que comenzó a operar a contar de ella.

Pues bien, la incorporación de los trabajadores independientes a los indicados regímenes previsionales, le otorgaban el derecho a acceder a pensiones por vejez, invalidez y muerte, y a cobertura de salud comunes, a través de los organismos médicos previsionales correspondientes, incluidos el pago de subsidios por enfermedad y maternidad, y sólo respecto de algunos sectores de tales trabajadores, al seguro de accidentes del trabajo y enfermedades profesionales, en la medida que disposiciones legales especiales les fueran incorporando.

\section{SITUACIÓN EN EL NUEVO SISTEMA DE PENSIONES PREVIA A LA REFORMA PREVISIONAL DEL AÑO 2008}

Ahora, el decreto ley $\mathrm{N}^{\circ} 3.500$, de 1980, de Nuevo Sistema de Pensiones, antes de su reforma por la ley $\mathrm{N}^{\circ} 20.255$, de $17.03 .2008^{7}$, se preocupó de la afiliación del trabajador independiente, en términos amplios y sin mayores limitaciones, al entender por tal a toda persona natural que, sin estar subordinada a un empleador, ejerce una actividad mediante la cual obtiene un ingreso, teniendo como renta imponible mensual aquella que el mismo interesado declare mensualmente en la Administradora en la cual se afilie, la que no podía ser inferior a un ingreso mínimo legal mensual ni superior al equivalente a 120 Unidades de Fomento.

Sin embargo, esta afiliación, que se configuraba simultáneamente con la primera cotización, que se efectuara en la Administradora, quedó entregada a la voluntad del trabajador, toda vez que se le otorgó la facultad de cotizar, y por ello de incorporarse al sistema, si lo estimaba pertinente.

Cabe señalar que la incorporación le otorgaba el derecho a pensiones por vejez, invalidez y sobrevivencia, del mismo sistema, y a la protección de salud pública o privada, efectuando la cotización legal correspondiente, lo que comprendía la atención médica y el pago de subsidios por incapacidad laboral por enfermedad común y por maternidad pre y post natal, para la trabajadora mujer. Para estos efectos de cobertura de salud y subsidios se le exigía a lo menos 12 meses de afiliación previa y a lo menos seis meses de cotizaciones, continuas o discontinuas dentro del período, sin perjuicio de haber enterado el último mes anterior a la licencia.

De lo anterior, se desprende que a partir del año 1981, se produjo un notorio avance en cuanto a la consideración del trabajador independiente en términos amplios, olvidándose de una

La ley No 20.255, fue publicada en el Diario Oficial de 17.03.2008. 
limitación de funciones, grupos o sectores específicos de ellos, que en la realidad constituyeron minorías privilegiadas, que tornaba discriminatoria la legislación que les beneficiaba frente al resto de la gran masa de trabajadores independientes o por cuenta propia a quienes no amparaba ninguna norma especial, como ocurrió con la legislación del Antiguo Sistema Previsional anterior al año 1981.

Con todo, si bien se abrió el derecho a la afiliación, e incluso entregando a la propia determinación del trabajador solicitarla, al igual que la fijación de la renta imponible sobre la cual deseaba cotizar entre los topes legales indicados, el propósito del legislador no se alcanzó a cabalidad, ni mucho menos, si los trabajadores independientes en general, cotizantes efectivos al Nuevo Sistema de Pensiones, a diciembre del año 2010 eran 91.442, y a igual mes del año 2011, 94.323, incremento poco relevante, pero que comienza a pronunciarse a diciembre de 2012 , a $107.350^{8}$, es decir, se conforma un aumento más notorio aunque siempre moderado de cotizantes, en un período anual muy significativo, si la afiliación y cotización de estos trabajadores de acuerdo a la nueva legislación que se les aplica en forma obligatoria comenzó el $1^{\circ}$ de enero de 2012, aun cuando no en forma perentoria como se verá.

\section{REGULACIÓN LEGAL A PARTIR DE LA REFORMA PREVISIONAL DEL AÑO 2008, A APLICARSE A CONTAR DEL 1 DE ENERO DE 2012}

La situación descrita anteriormente llevó a que en la Reforma Previsional del año 2008, de la ley $\mathrm{N}^{\circ} 20.255$, de trascendencia para la seguridad social chilena, se optara, entre otras materias, por la incorporación obligatoria de un sector de trabajadores independientes al Nuevo Sistema de Pensiones, a través de un mecanismo de cotización gradual en cuanto a su monto y en el tiempo, a contar del $1^{\circ}$ de enero de 2012, no obstante que regiría solo para aquellos trabajadores independientes que perciben honorarios en su actividad y los que emiten boletas de prestación de servicios, manteniéndose para el resto de tales trabajadores la posibilidad de la afiliación voluntaria, como se contemplaba antes de la reforma, y ya se esbozó en su contenido con anterioridad.

Lo importante es que de concretarse la afiliación y cotización al Sistema, deja al trabajador independiente obligado en la misma condición o situación de derechos previsionales que el trabajador dependiente, respecto del régimen de pensiones y de las demás prestaciones de seguridad social, como salud, accidentes del trabajo y enfermedades profesionales y asignación familiar, entre otras, con lo cual se le mejora respecto de los afiliados al Antiguo Sistema de Pensiones, y a la vez, se persigue el reconocimiento de la igualdad del tratamiento legal del trabajador en general en materia de seguridad social, lo que sin duda es positivo en una política social de integración del sector trabajo.

Cabe destacar, por otro lado, que la Reforma respetó los derechos adquiridos de los trabajadores independientes afiliados a alguna de las ex Cajas de Previsión del régimen antiguo, administradas por el actual Instituto de Previsión Social, órgano del sector público, al establecer, por medio del artículo 92 I del D.L. $N^{\circ} 3.500$, ya reformado, que no estarán obligados a cotizar de acuerdo a las nuevas disposiciones legales, y continuarán rigiéndose por las normas de sus respectivos regímenes previsionales.

\subsection{CONTENIDO BÁSICO DE LA NUEVA LEGISLACIÓN}

Ahora bien, en relación con la nueva regulación de la afiliación y cotización del trabajador independiente, el artículo 89 del D.L. $N^{\circ} 3.500$ vigente, en su texto modificado por la ley

Estadísticas de la Superintendencia de Pensiones, abril de 2013. 
$\mathrm{N}^{\circ}$ 20.255, llamada de Reforma Previsional, dispone la afiliación obligatoria al Sistema de toda persona natural que, sin estar subordinada a un empleador, ejerza individualmente una actividad mediante la cual obtiene rentas del trabajo gravadas por el artículo $42 \mathrm{~N}^{\circ} 2$ de la Ley sobre Impuesto a la Renta, contenido en el decreto ley $\mathrm{N}^{\circ} 824$, de 1974, del Ministerio de Hacienda, por las cuales debe emitir boletas de honorarios o de prestación de servicios. Estas rentas corresponden a ingresos provenientes del ejercicio de profesiones liberales, o de cualquiera profesión u ocupación lucrativa, entendiéndose por esta la actividad ejercida en forma independiente por personas naturales y en la cual predomine el trabajo personal, basado en el conocimiento de una ciencia, arte, oficio o técnica por sobre el empleo de maquinarias, herramientas, equipos u otros bienes de capital. Se incluyen los ingresos percibidos por los auxiliares de la administración de justicia por los derechos que conforme a la ley obtienen del público, los corredores que sean personas naturales cuyas rentas provengan exclusivamente de su trabajo o actuación personal, y los obtenidos por sociedades de profesionales, que presten exclusivamente servicios o asesorías profesionales.

De esta manera, son obligados los trabajadores que perciben honorarios por actividades profesionales $\mathrm{u}$ oficios independientes, $\mathrm{y}$ emiten las boletas correspondientes, y los que emiten boletas de prestación de servicios a terceros, y boletas por participación en rentas de sociedades profesionales que no hayan optado por declarar la renta en $1^{\text {a }}$ Categoría de la Ley de Impuesto a la Renta.

La nueva normativa, contenida en la ley $\mathrm{N}^{\circ} 20.255$, que dispone que los trabajadores independientes antes referidos estarán obligados a efectuar cotizaciones previsionales para pensiones, y además, para el seguro de accidentes del trabajo y enfermedades profesionales, y para salud, lo hace en una gradualidad que la misma norma legal establece, no obstante que se pueda renunciar anualmente a cotizar, hasta el año 2014, como se analizará.

\subsection{Gradualidad de LA INCORPORACIÓN DEL TRABAJADOR INDEPENDIENTE, CON POSIBILI-}

\section{DAD DE RENUNCIA EN FORMA LIMITADA}

El legislador ha sido muy cauto y evitó imponer de buenas a primeras una incorporación obligatoria, y consiguiente cotización, a quienes prácticamente nunca la tuvieron, en armonía con un afán de exigir tales deberes plenamente una vez que se asentaran en la voluntad del obligado, venciendo una conducta de indiferencia u omisión, arraigada, y también, cuando este pudiere apreciar las ventajas y los beneficios de hacerlo.

Esta gradualidad es la siguiente ${ }^{9}$ : desde el $1^{\circ}$ de enero del 2012, se debe cotizar y por ello es obligación incorporarse o afiliarse al Sistema, respecto del $40 \%$ de la renta imponible, para pensiones y para el seguro de accidentes del trabajo y enfermedades profesionales, pudiendo renunciar a cotizar si así se manifiesta de modo expreso, anualmente. Desde el $1^{\circ}$ de enero de 2013 , se debe cotizar respecto del $70 \%$ de la renta imponible, para la misma cobertura indicada, salvo que igualmente se renuncie de manera expresa. Desde el $1^{\circ}$ de enero del 2014, se debe cotizar sobre el $100 \%$ de la renta imponible, a menos que igualmente se ejerza la opción de renuncia. Con todo, a partir del $1^{\circ}$ de enero de 2015 , se debe igualmente cotizar por el $100 \%$ de la renta imponible, pero ya sin la posibilidad de renuncia.

De esta forma, sólo a contar de esta última fecha existirá propiamente afiliación y cotización obligatoria para este sector de trabajadores. Cabe agregar, que desde el $1^{\circ}$ de enero del año 2018, se deberá cotizar por el $100 \%$ de la renta imponible para salud, sin posibilidad de renuncia.

La gradualidad se encuentra establecida en el artículo 29 transitorio de la ley No 20.255 . 
Esta gradualidad en la obligación de cotización tendría justificaciones muy plausibles. Una de ellas sería la necesidad de crear espacios para ejecutar acciones destinadas a una educación previsional efectiva de los trabajadores independientes, no sólo en cuanto al sentido, beneficio y aplicación de la nueva normativa, sino que también respecto del contenido y alcances del Nuevo Sistema de Pensiones al cual ingresan, que les es normalmente desconocido, como a la vez, la utilidad que les significa estar protegidos por un seguro social de accidentes del trabajo y enfermedades profesionales, y para cobertura de atención médica y pago de subsidios por enfermedad y maternidad, como igualmente, asignaciones familiares, fundamentalmente, con la debida información acerca de las prestaciones y requisitos correspondientes de estos distintos regímenes legales de seguridad social.

Otra razón para la gradualidad podría estar en la posibilidad de emprender actividades orientadas a crear un cambio cultural en el comportamiento del trabajador independiente, fomentando conductas de previsión de contingencias futuras, amparadas por la seguridad social, que generalmente este tipo de trabajadores confía cubrirlas con su propio esfuerzo, muy natural a su condición de trabajadores movidos por iniciativas de superación individual autónomas, desplegadas sin limitación de sacrificio personal y de edad, recurriendo a los posibles ahorros que se hayan podido acumular, si les ha sido factible, o a la liquidación de sus instrumentos productivos, en el peor de los casos, sin una presencia institucional o previsional. Otra explicación, específicamente en cuanto a la gradualidad en la posibilidad de renunciar expresamente a cotizar, podría estar en una estrategia del legislador de utilizar la conducta de omisión del trabajador independiente frente a lo previsional, lo que sería aplicable justamente para considerarlo obligado a cotizar.

En efecto, la incorporación ideal del trabajador independiente a un sistema de previsión podría obedecer a su interés por tener para sí y su grupo familiar la cobertura de prestaciones aseguradas, en pensiones, salud, asignaciones familiares, y las correspondientes a accidentes del trabajo y enfermedades profesionales, contingencias que ya no se cubrirán con su sólo esfuerzo y trabajo, lo que le induciría activa y conscientemente a afiliarse y cotizar al sistema, sino que también podría obedecer dicha incorporación en que la ley utilice su habitual desapego hacia los mecanismos de apoyo previsional, de modo tal que si no se manifiesta oportunamente de manera expresa la renuncia a cotizar, quedaría automáticamente obligado a hacerlo, lo que tendría en todo caso sentido sólo durante un período acotado, que en la nueva normativa sería hasta el año 2014, como se ha establecido, por cuanto a la larga, se cambiará el hábito, y seguramente se estará muy atento a los alcances de la ley previsional.

\subsection{Posibilidad DE RENUNCIA A COTIZAR OBLIGADAMENTE COMO TRABAJADOR INDEPEN- DIENTE}

Como se ha indicado anteriormente, el legislador habría recurrido a un mecanismo muy especial para lograr la afiliación y cotización de estos trabajadores, utilizando tal vez precisamente la inercia o desinterés que presentan ante lo previsional, como característica propia, consistente en que si no rompen la inercia o conducta de omisión manifestando, dentro de un plazo, formalmente que no desean cotizar durante cada uno de los años 2012, 2013 y 2014, se quedará obligado a hacerlo.

Esta estrategia empleada por la ley, cuyo resultado definitivo podrá apreciarse a partir del año 2015, ya ha tenido sus manifestaciones, si a enero de 2013 se han presentado aproximada- 
mente 240.000 renuncias $^{10}$; en la primera semana de abril irían en 518.000, y el día 25 del mismo mes serían $600.000^{11}$, esperándose que al día 30 , cuando venza el plazo para la presentación de la declaración de impuesto a la renta, -renuncia que debe hacerse antes de esta presentación- sean aún muchas más, de un total de algo más de 1.000.000 de obligados, aproximadamente. De esta manera, no obstante, subirá la cantidad de cotizantes, aun cuando lo interesante sería poder determinar cuántos cotizaron de manera consciente y activa, y cuantos por inadvertencia y por no haber renunciado oportunamente.

Este sistema se asemeja a la propuesta de algunos autores partidarios de una tercera opción para lograr la incorporación y más bien cotización de estos trabajadores, distinta a una obligatoriedad perentoria de la ley dentro de un plazo determinado, o a contemplar incentivos para hacerlo, como podría ser la incorporación simultánea a otras prestaciones de seguridad social, como asignaciones familiares, o accesos especiales a salud, o de rebajas tributarias, cuál sería, como se ha indicado, la basada en ocupar la conducta de omisión de estos trabajadores hacia lo previsional, o su desinterés o prescindencia tradicional al respecto, para alcanzar el objetivo de obtener su cotización.

En efecto, tal como lo señalan Solange Berstein, Gonzalo Reyes y Francisco Pino en un estudio titulado "Trabajadores independientes: ¿ Incentivarlos u obligarlos a cotizar? Una tercera opción" ${ }^{12}$, habría una tercera vía cual sería la llamada cotización por omisión, que se explicaría en "la inercia de tales trabajadores por cotizar en el sistema previsional, postergando la decisión por el solo hecho que tomarla requiere una acción activa, y si en cambio, esta acción fuera necesaria para dejar de cotizar, la propia inercia haría que muchos independientes siguieran cotizando en el sistema de pensiones".

Los autores citados se preguntan cómo se implementa un sistema en que la opción por defecto sea que estos trabajadores coticen. Se sugiere utilizar la declaración de impuesto a la renta anual para tal efecto, en el evento de tener derecho a devolución, lo que se informaría al contribuyente que una parte de dicha devolución de impuestos se puede destinar a cotización previsional, dándole la opción de rechazar tal aplicación, pero si no manifiesta su voluntad contraria, dicha parte iría a la cuenta de capitalización individual en una AFP.

Esta posición se basaría, como los mismos autores lo indican, en un área de estudios surgida en la literatura económica en los últimos años, denominada "Economía del Comportamiento", que propone una serie de modelos alternativos a los de racionalidad clásicos que tratan de explicar una serie de conductas que desde otro punto de vista aparecen como contradictorias, en los agentes económicos, como sería la postergación de decisiones importantes durante un período, aún cuando después se arrepienta de no haberlo hecho.

Se da el caso, que la ley justamente estableció destinar la devolución de impuesto a la renta a cotizaciones, salvo que se haya renunciado a cotizar a través de una declaración de no desear hacerlo, ante el mismo Servicio de Impuestos Internos, desde junio y hasta el mes de abril de cada año, y hasta el año 2014, y de no hacerlo, se queda obligado a cotizar. Por ello, si no se ha efectuado cotizaciones en una cantidad suficiente, se imputará por Tesorería General de la República la devolución del impuesto a la renta a dichas cotizaciones faltantes ${ }^{13}$.

\footnotetext{
10 Ciedess. Corporación de Investigación, Estudio y Desarrollo de la Seguridad Social.

11 Valencia, Roberto. Por qué a los independientes les conviene cotizar en una AFP, en: www.lanacion.cl (sitio Web consultado el 27 de abril de 2013).

12 Opúsculo "En Foco” N No 66. Expansiva.

13 La renuncia se debe presentar en el sitio Web del Servicio de Impuestos Internos, www.sii.cl, con la formalidad de una declaración
} 


\subsection{BASE IMPONIBLE Y DETERMINACIÓN DEL TOTAL A COTIZAR}

Corresponde precisar, que la renta imponible anual sobre la cual se deberá cotizar es la equivalente al $80 \%$ de la suma de los honorarios brutos percibidos en el año calendario anterior, reajustada según la variación del Índice de Precios al Consumidor, IPC, sin ningún tipo de descuento, que determine el Servicio de Impuestos Internos, basado en la declaración anual de impuesto a la renta del contribuyente, con un tope base de un ingreso mínimo mensual, ( $\$ 193.000$, ó US\$ 400) y un máximo que resulte de multiplicar por 12 el tope máximo general imponible ${ }^{14}$, lo que para el año 2013 alcanza a 843,6 UF anual, ( \$ 19.234.080, o US\$ 40.070 ${ }^{15}$ aprox.). Respeto de dicho $80 \%$ se aplicará la gradualidad del $40 \%$, 70\% y 100\% del mismo por los años 2012, 2013 y 2014, respectivamente, lo que dará la renta imponible afecta a cotización en cada uno de estos períodos.

El Servicio de Impuestos Internos, en el proceso de la operación renta de cada año, fijará las cotizaciones a pagar por estos trabajadores para pensiones, las que se compensarán con las asignaciones familiares a que se tenga derecho, si procede, con la retención del 10\% del impuesto sobre boletas de honorarios o de prestación de servicios declaradas, menos los pagos provisionales mensuales de cotizaciones que hubiere efectuado voluntariamente el trabajador. En el caso que la compensación con las asignaciones familiares, retención del 10\% y pagos provisionales no alcance a cubrir el total de las cotizaciones anuales, se debe enterar la diferencia en la Administradora de Fondos de Pensiones de la afiliación, a menos que se impute a ella la devolución de impuesto a la renta. Las cotizaciones para salud y accidente del trabajo y enfermedades profesionales se pagarán mensualmente, y el Servicio de Impuestos Internos hará la reliquidación anual al respecto.

Cabe señalar, que acorde al inciso $2^{\circ}$ del artículo 89 del D.L. $N^{\circ} 3.500$, la primera cotización efectuada a una Administradora de Fondos de Pensiones, por el trabajador independiente produce su afiliación al Sistema, y por ende su obligación a afiliarse al seguro de accidentes del trabajo y enfermedades profesionales en la entidad que corresponda, y al seguro de salud, ya sea público, en el Fondo Nacional de Salud, FONASA, salvo que se opte por el privado, de una Institución de Salud Previsional o Isapre, aún cuando la cotización correspondiente para salud será obligatoria sólo a partir del $1^{\circ}$ de enero de 2018 , según la gradualidad del artículo 29 transitorio de la ley $\mathrm{N}^{\circ}$ 20.255, pudiendo hacerse con anterioridad voluntariamente para tener derecho a las respectivas prestaciones.

\subsection{SitUACIÓN DE LOS OTROS TRABAJADORES INDEPENDIENTES QUE NO PERCIBEN HONORA-} RIOS NI EMITEN BOLETAS

La ley dispone que si el trabajador independiente no percibe rentas de las señaladas en el $\mathrm{N}^{\circ}$ 2 del artículo 42 de la ley de la renta, no está obligado a cotizar, pero podrá hacerlo como afiliado voluntario, algo parecido a como lo estaba antes de la Reforma, que rige para toda persona natural que no ejerza una actividad remunerada, por lo que puede efectuar cotizaciones para pensiones en una Administradora de Fondos, y ahora para salud en el organismo correspondiente, y tener derecho también a asignaciones familiares.

jurada habilitada en el mismo sitio, entre los meses de junio y abril de cada año, y antes de la presentación de la declaración de impuesto a la renta, cuyo plazo vence el último día del mes de abril.

14 El tope máximo imponible para el año 2013 para el Nuevo Sistema de Pensiones es de 70,3 Unidades de Fomento. Los topes mínimos y máximos son los vigentes al 31 de diciembre del año correspondiente a las rentas.

15 Se ha considerado un valor promedio de $\$ 480$ por 1 US $\$$. 
Es decir, no están obligados a cotizar, pero de hacerlo quedan en una situación similar a la de los obligados, con lo cual el legislador no los ha abandonado, por el contrario, les trata en igualdad de condiciones a todos.

Cabe agregar, que las cotizaciones que efectúen estos trabajadores para los fines indicados tendrán el carácter de cotización previsional para efectos tributarios del impuesto a la renta, es decir constituyen un gasto, lo que ya es un incentivo.

Como comentario, lo antes descrito constituirá en la práctica la realidad más generalizada entre los trabajadores independientes, quienes no obstante, podrán verse inducidos a incorporarse al sistema, solo si con ello mejoran su situación futura y logran una efectiva protección previsional.

\subsection{TRABAJADORES INDEPENDIENTES QUE SON EXCLUIDOS}

De acuerdo a la ley, quienes no obstante tener la calidad de trabajadores independientes no están obligados a afiliarse ni a cotizar son: Los que al $1^{\circ}$ de enero de 2012 hayan tenido 55 años de edad o más, si son hombres, o 50 o más, si son mujeres, lo que no impediría que puedan efectuar cotizaciones como voluntarios. La explicación estaría en que no lograrían acumular en sus cuentas de capitalización una cantidad de fondos importante para financiar una pensión, que para vejez procede a los 65 años del hombre y a los 60 de la mujer. Tampoco podrán hacerlo los afiliados que coticen mensualmente como dependientes por una remuneración igual al tope imponible mensual, que para este año 2013, es el equivalente a 70,3 Unidades de Fomento, es decir \$ 1.607.705 ó US\$3.348. Igualmente, no podrán hacerlo los afiliados al Instituto de Previsión Social, IPS, que pertenecen al régimen antiguo de pensiones; los de la Dirección de Previsión de Carabineros y de la Caja de Previsión de la Defensa Nacional, como los acogidos a pensión por vejez, vejez anticipada o invalidez total del Nuevo Sistema de Pensiones. Se exceptúa a los pensionados por invalidez del seguro de accidentes del trabajo y enfermedades profesionales, quienes podrán incorporarse.

Se hace pertinente comentar, respecto de este acápite y del anterior, que la incorporación del trabajador independiente a la seguridad social tiene estrecha relación con las políticas públicas de fomento del emprendimiento de las personas, o de incentivo para que inicien o desarrollen actividades productivas de libre iniciativa, como estrategia de auto superación y crecimiento personal y familiar, lo que tiene especial relevancia en Chile, debido a que aproximadamente el $80 \%$ de la fuerza laboral empleada corresponde a la pequeña y mediana empresa, a cargo generalmente de empresarios trabajadores independientes que de acuerdo a la nueva normativa su afiliación y cotización seguirá siendo voluntaria, mientras no se legisle en orden a incorporarlos obligadamente, cuando se aprecie las ventajas de la normativa en vigor, si ellos no están obligados a emitir boletas de honorarios o de prestación de servicios.

\subsection{Cobertura de otras PRESTACIONES, PARA EL TRABAJAdOR INDEPENDIENTE, ADEMÁs DE PENSIONES}

Como ya se expresara, la nueva normativa de la ley $\mathrm{N}^{\circ} 20.255$, obliga al trabajador independiente que percibe honorarios y emite boletas a incorporarse al Sistema de Pensiones, pero también lo hace respecto de otras prestaciones de seguridad social, como son el seguro de accidentes del trabajo y enfermedades profesionales, contenido en la ley $\mathrm{N}^{\circ} 16.744$, de 1968; para salud, ya sea del sistema público o de las Isapres, regulado en el DFL No 1, de 2005, del Ministerio de Salud, y para asignaciones familiares, regido por el DFL No 150, de 1981, del Ministerio del Trabajo y Previsión Social, aún cuando para este último no se cotiza, si se financia con fondos fiscales. 
Por esta vía, se inserta al trabajador independiente obligado a cotizar en un espectro amplio de seguridad social, lo que le puede significar un incentivo para participar del sistema, por cuanto obtendrá otros beneficios importantes para sí y su familia, en el corto o mediano plazo, especialmente a través de las prestaciones familiares y protección de salud, sin perjuicio del seguro de accidentes del trabajo y enfermedades profesionales.

Desarrollaremos a continuación la aplicación de estos regímenes al trabajador independiente.

\subsubsection{Incorporación al seguro de accidentes del trabajo y enfermedades profesionales}

La ley No 16.744, que contiene este seguro, es sabido que conforma un sistema completo y orgánico de prestaciones médicas y pecuniarias, de subsidios por incapacidad laboral, pensiones por invalidez y muerte, e indemnizaciones en caso de daños o detrimentos corporales, originados por accidentes producidos a causa o con ocasión del trabajo, o por enfermedades profesionales contraídas directamente por el ejercicio de una determinada actividad u oficio laboral.

Pues bien, el decreto supremo No 67, del 2008, del Ministerio del Trabajo y Previsión Social ${ }^{16}$, se ocupa de reglamentar la incorporación de los trabajadores independientes al indicado seguro social, para lo cual se entenderán afiliados al Instituto de Seguridad Laboral, ISL, salvo que voluntariamente se adhieran a una Mutualidad de Empleadores autorizada, como organismo administrador privado de este seguro. Para estos efectos, las instituciones indicadas deberán requerir los antecedentes personales y del trabajo desempeñado por el trabajador.

Se considera que son accidentes del trabajo no solo los producidos a causa o con ocasión de las labores, sino que además los de trayecto directo, de ida o de regreso, entre la habitación y el lugar de trabajo, como también entre dos lugares de trabajo, o cuando se dirija desde éste a otro lugar de desempeño aún cuando sea de dependiente, o viceversa, de ser el caso. En materia de enfermedades profesionales, podrá acreditar ante el organismo administrador el carácter profesional de alguna enfermedad contraída en el trabajo aún cuando no esté incluida en la lista no taxativa contenida en el decreto supremo No 109, de 1968, del Ministerio del Trabajo y Previsión Social.

Para tener derecho a las prestaciones médicas y pecuniarias del seguro, requerirán estar al día en el pago de las cotizaciones para pensiones, para salud y para el mismo seguro de la ley No 16.744. Se considera que se está al día si no se registra un atraso superior a dos meses en el pago.

Las cotizaciones deberán enterarse mensualmente, al respectivo organismo administrador, tanto la básica general, actualmente de 0,95, más la adicional diferenciada, según el mayor riesgo de la actividad laboral desempeñada, tal como rige respecto de los trabajadores dependientes. La base será la misma renta para la cual se cotiza para pensiones. Cabe comentar que como estos trabajadores carecen de empleador, ellos mismos asumen sobre sí las obligaciones que recaen sobre éste en relación a sus trabajadores dependientes, como son el cargo del costo de las cotizaciones, y por el mayor riesgo propio de la actividad laboral, como las medidas de prevención de las contingencias.

De no pagarse la cotización en el plazo legal general vigente para los trabajadores dependientes, quedarán sujetos a las normas de cobranza de la ley $\mathrm{N}^{\circ} 17.322$, en materia de sanciones y recargos, y al procedimiento ejecutivo de cobranza.

${ }^{16}$ El decreto supremo No 67, del 2008, del Ministerio del Trabajo y Previsión Social, fue publicado en el Diario Oficial de 30.09 .2008 . 
Cabe consignar, que efectuada mensualmente la cotización para este seguro ello impedirá que el trabajador pueda renunciar una vez al año a cotizar para pensiones, como se lo permite la ley hasta el año 2014.

En materia de prevención de accidentes y enfermedades profesionales, deben cumplir todas las exigencias de medidas de higiene y seguridad en el lugar de trabajo que les prescriba el organismo administrador, el cual está obligado a proporcionarle la asistencia técnica al respecto. ${ }^{17}$

\subsubsection{Incorporación al régimen de prestaciones familiares}

El decreto supremo No 26, de 2012, del Ministerio del Trabajo y Previsión Social ${ }^{18}$, reglamenta la incorporación del trabajador independiente que sea cotizante como beneficiario del Sistema Único de Prestaciones Familiares, del DFL No 150, de 1981, del Ministerio antes indicado. Se le exige estar al día en el pago de las cotizaciones para pensiones, salud y accidentes del trabajo y enfermedades profesionales, dado que para este Sistema Único no se cotiza al ser financiado con fondos fiscales, para acceder al pago de las asignaciones familiares y maternales correspondientes. Se entiende que se está al día si al 31 de diciembre del año anterior se tiene íntegramente pagadas las cotizaciones determinadas en el proceso de declaración de impuesto a la renta por dicho año.

Ahora, el pago de las asignaciones le será efectuado anualmente en el proceso de declaración del impuesto a la renta, mediante su compensación con las cotizaciones que debió enterar para pensiones, para salud y para el seguro de accidentes del trabajo y enfermedades profesionales. De restar un saldo a favor del trabajador, le será pagado directamente por Tesorería General de la República.

El Instituto de Previsión Social, IPS, deberá informar anualmente al Servicio de Impuestos Internos la nómina de los trabajadores independientes que al 31de diciembre del año anterior tenían cargas de familia reconocidas, y si estaban al día en el pago de las cotizaciones previsionales.

Cabe agregar, por otra parte, que el decreto supremo No 27, de 2012, del Ministerio del Trabajo y Previsión Social ${ }^{19}$, ha reglamentado la afiliación voluntaria de estos trabajadores a las Cajas de Compensación de Asignación Familiar, regidas por ley № 18.833, siempre que hayan pagado las cotizaciones en los últimos 30 días, Esta afiliación les dará derecho no solo a las asignaciones familiares sino que a las prestaciones adicionales que tengan autorizadas estas Cajas, como crédito social y prestaciones complementarias. Con el fin de contribuir al financiamiento de estas prestaciones, cada Caja establecerá un aporte de cargo del afiliado, fijo o variable, mensual, que no podrá exceder del $2 \%$ de la renta imponible para pensiones.

\subsubsection{Incorporación para cobertura de salud}

Los trabajadores independientes obligados a cotizar para el régimen de pensiones, se entienden por la ley por esta sola circunstancia incorporados al sistema de prestaciones de salud para sí y sus cargas de familia, contenido en la Ley de Salud, o DFL No 1, de 2006 del Ministerio de Salud $^{20}$. Para tener derecho a las prestaciones de carácter médico, incluido el sistema de libre elec-

\footnotetext{
17 Esta materia se encuentra tratada en Circular No 2483, de 03.10.2008, de la Superintendencia de Seguridad Social.

18 El decreto supremo No 26, de 2012, del Ministerio del Trabajo y Previsión Social, fue publicado en el Diario Oficial de 04.02.2012.

19 El decreto supremo No 27, de 2012, del Ministerio del Trabajo y Previsión Social, fue publicado en el Diario Oficial de 04.02.2012.

20 El Decreto con Fuerza de Ley No 1, de 2006, del Ministerio de Salud, que contiene el texto fusionado de importantes leyes en materia de salud, fue publicado en Diario Oficial de 21.04.2006.
} 
ción, deben estar al día en el pago de la cotización del 7\% correspondiente, lo que significa que será suficiente que el último mes anterior a impetrar el beneficio se encuentre pagado, o bien, alternativamente, haber enterado a lo menos seis meses de cotizaciones continuas o discontinuas en los doce meses anteriores a requerir la prestación, como se requiere respecto de los trabajadores independientes en general, requisito este último que es exigible copulativamente con el anterior, de estar al día, para tener derecho al pago de los subsidios por enfermedad común o por maternidad, al igual que rige para todos los trabajadores independientes. Cabe agregar, que los subsidios por enfermedad común y por maternidad, pre y post natal y parental, se calcularán sobre el promedio de las rentas de los últimos seis meses anteriores a la licencia médica. Atendido que la cotización del $7 \%$ para salud en la forma establecida en la ley será obligatoria a partir del $1^{\circ}$ de enero de 2018 , según la gradualidad del sistema, antes de esta fecha se enterarán las cotizaciones de acuerdo a las disposiciones vigentes anteriores a la publicación de la ley 20.255, esto es, al 17.03.2008, con lo cual se podrá acceder en el intertanto a las prestaciones de salud y de subsidios correspondientes, y por la misma razón, esta cotización no podrá ser pagada mediante imputación obligada de devolución de impuesto a la renta con anterioridad a enero del 2018.

\section{CONCLUSIÓN}

A modo de conclusión, es posible señalar que si bien se está en presencia del segundo año de vigencia de la nueva normativa de incorporación obligatoria de un sector de trabajadores independientes a un sistema previsional, estimamos que resulta prematuro analizar los efectos de su afiliación y cotización en la realidad de estos trabajadores en la previsión social chilena, dado que ello sólo podrá ser evaluado en mejor forma desde que exista el imperativo de cotizar, sin posibilidad de renuncia, lo que sucederá a partir del año 2015.

No obstante lo anterior, aparece como un síntoma de lo que podría ocurrir a contar de dicho año, el hecho de la importante cantidad de renuncias de cotizar que se han presentado este año, sobre el $50 \%$ de los obligados, lo que estaría indicando que estos trabajadores a los cuales se aplica la ley, que es un segmento de ingresos medianos y altos, no desean realmente acogerse a un sistema previsional, a menos que se establezca un incentivo real que les induzca a hacerlo.

De mantenerse esta tendencia tan relevante a no desear cotizar, a partir del año 2015, cuando ya no exista la posibilidad de renuncia, el problema de la evasión será importante, y por ello hay tiempo para buscar alguna solución, en especial para cuando la retención de devolución de impuestos no sea suficiente para cubrir el monto de las cotizaciones de estos trabajadores.

Asimismo, es de esperar que a la larga no se produzca como efecto colateral, una evasión tributaria de estos contribuyentes, en la emisión de boletas de honorarios o de prestación de servicios.

En todo caso, como se ha analizado, sólo podrá haber efectos limitados, dado que la normativa ha comprendido a un sector muy acotado de trabajadores independientes, situación que podría mejorar si los no obligados a incorporarse optaran por hacerlo, voluntariamente, al verificar las ventajas que ello acarrea entre quienes si han debido afiliarse y cotizar, lo que igualmente requiere de tiempo.

Sin perjuicio de lo expresado, es posible observar desde ya un aumento de los trabajadores cotizantes, que de 94.323 al 31 de diciembre de 2011, mes anterior al de la obligación de incorporación, subieron a 107.350 al 31 de diciembre de 2012, es decir se incrementaron un 13,8\%, y a 134.353 , al $1^{\circ}$ de enero de 2013 , esto es, un $42,4 \%$ respecto del mes previo al de inicio del sistema, 
según datos de la Superintendencia de Pensiones ${ }^{21}$. Lo que significa que se trata de una tarea en pleno desarrollo.

${ }_{21}$ Centro de Estadísticas Superintendencia de Pensiones. Abril de 2013. 